\title{
A two-dimensional $(x-z)$ model of tidal straining in the Rhine ROFI
}

\author{
ALEJANDRO J. SOUZA* and IAN D. JAMES $\dagger$ \\ (Received 11 August 1994; in revised form 17 January 1995; accepted 22 March 1995)
}

\begin{abstract}
Recent observations of the Rhine ROFI system in the North Sea suggest that the dynamics and structure are very variable, due to the fact that the system responds very rapidly to changes in the stirring conditions due to tides and winds. They also show very strong semi-diurnal variability, which is the result of the interaction between tidal straining and the cross-shore density gradients. This hypothesis is tested using a two-dimensional slice model. The model is successful in reproducing the qualitative behaviour of the observations, with the semi-diurnal oscillations in stratification of the right amplitude and at the same phase of the tidal cycle as the observations. The model also shows the effect of the stratification on generating the cross-shore tidal shear which then interacts with the main density gradients, hence the semi-diurnal variability in stratification. The model confirms previous hypotheses that suggest the importance of wind direction in enhancing or suppressing stratification.
\end{abstract}

\section{INTRODUCTION}

The $2200 \mathrm{~m}^{3} \mathrm{~s}^{-1}$ average freshwater input from the Rhine into the North Sea generates a large ROFI (region of freshwater influence) which covers the entire Dutch coast, with the north-eastern boundary at about $100 \mathrm{~km}$ from the source and the western boundary at about $30 \mathrm{~km}$ from the coast (Simpson et al., 1993). The presence of the freshwater in this area exerts an important influence on the system's dynamics and water column stability. In previous papers (e.g. Simpson et al., 1993; Simpson and Souza, 1995) we have described the basic processes operating in the Rhine ROFI with the aid of observations made in 1990 and 1992 as part of the EC-funded MAST PROFILE project.

The basic competiton between the stratifying effect of the buoyancy input and the mixing influence of stirring by the tidal flow, winds and waves leads to an alternation between periods of strong stratification and complete vertical mixing in the Rhine ROFI in much the same way as has been observed elsewhere (e.g. Sharples and Simpson, 1995). The periodic variation in the intensity of tidal stirring tends to impose a fortnightly cycle on the system with stratification breaking down at, or soon after, spring tides. At the same time, variations in wind and wave conditions (Munchow and Garvine, 1993) as well as fluctuations in river discharge introduce more random components of variability. The

*School of Ocean Sciences, University College North Wales, Menai Bridge, Gwynedd LL59 5EY, U.K. †Proudman Oceanographic Laboratory, Bidston Observatory, Birkenhead, Merseyside L43 7RQ, U.K. 
competition between stabilizing and stirring forces is well visualized in the laboratory experiments of Linden and Simpson (1988), with the important addition in the real world of the effects of the Earth's rotation acting to limit the spreading of the density current, which gets deflected parallel to the coast forming a baroclinic contribution to the northflowing current along the Dutch coast.

Recent observations have shown how the presence of this mean stratification modifies the tidal ellipses (Visser et al., 1994; Souza and Simpson, 1995), increasing the offshore tidal shear, which is then allowed to interact with the cross-shore density gradients introducing strong semi-diurnal variability in stratification (Simpson and Souza, 1995).

The observations discussed by Simpson and Souza (1995) suggest that the processes of stratification in the Rhine ROFI are two-dimensional $(x-z)$ and respond in more or less the same way in the entire ROFI, with negligible influence of alongshore density gradients, which are an order of magnitude smaller than the cross-shore density gradients. To test this hypothesis, a two-dimensional $(x-z)$ slice model has been developed. The model uses an idealized flat bottom topography and a Kelvin wave propagating along the Dutch coast.

The model is successful in qualitatively reproducing the basic features of the observations and highlights the interactions between stratification and the cross-shore tidal shear.

\section{OBSERVATIONS}

The observations are part of an extensive observational campaign carried out on board the research vessel R.R.S. Challenger, from 2 to 17 September 1992. The time series were collected at mooring A (Fig. 1), located about $30 \mathrm{~km}$ downstream from the Rhine source and about $10 \mathrm{~km}$ from the coast. The mooring, which was designed to determine water column structure and flow, was equipped with four current meters at depths of approximately $1,10,13$ and $16 \mathrm{~m}$, each of which were capable of measuring temperature and salinity. The current meters were supplemented by the use of a Proudman Oceanographic Laboratory (POL) bottom-mounted $1 \mathrm{MHz} \mathrm{ADCP}$, which gives a greater vertical resolution.

In order to put the time series into a spatial context, we undertook CTD observations using the SEAROVER undulator which provides rapid sampling of temperature, salinity, fluorescence and optical beam transmittance from the surface to within $3 \mathrm{~m}$ from the bottom and has a horizontal resolution of about $300 \mathrm{~m}$. In this particular work we will show the observations carricd out at line $\mathrm{N}$ offshore from Noordwijk (Fig. 1), where a continuous $25 \mathrm{~h}$ survey was carried out between 16 and 17 September 1992 (Julian days 260 and 261).

The present observations are discussed in more detail in previous papers (e.g. Simpson and Souza, 1995; Souza and Simpson, 1995). The data suggest that the tides alone are not enough to mix the water column and that the wind is the dominant factor in the stirring processes. An even more important result is the presence of strong semi-diurnal variability of stratification, which is observed whenever stratification is present, has a value similar to the mean stratification and is a characteristic of the entire ROFI system.

An example of the time series at mooring $A$ is shown in Fig. 2. It is important to note that the tidal straining, tidal elevation and the alongshore velocity are in phase, while there is a slight phase lag in the stratification, which might be due to the interaction with the inertialimited density circulation and to mixing effects or even to alongshore advection. This is 


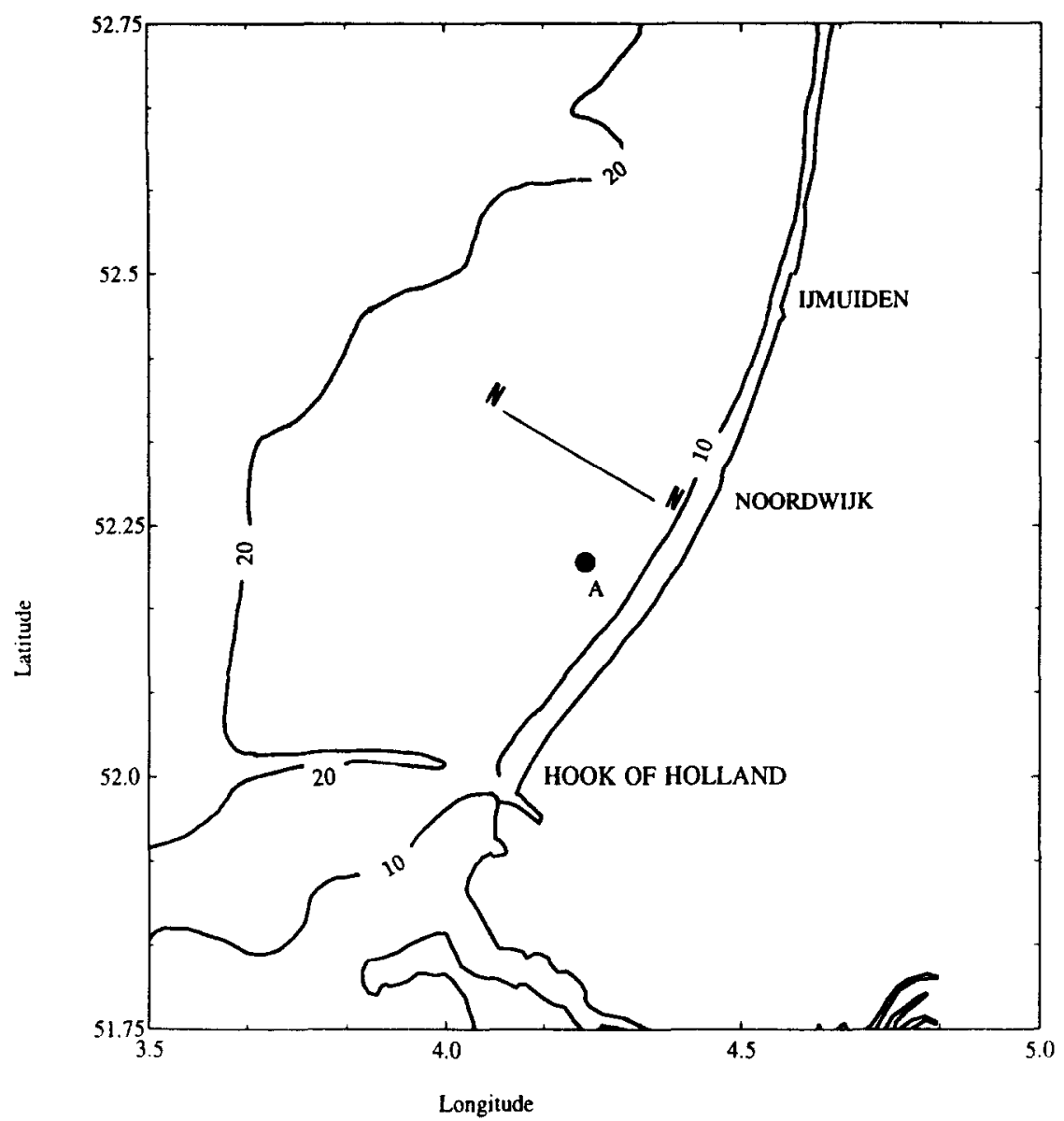

Fig. 1. Study area showing bathymetry in $\mathrm{m}$; the position of mooring $A(\cdot)$ and the SEAROVER line $\mathrm{N}$.

different from the straining-elevation phase relation observed in Liverpool Bay, due to the fact that the tidal motion there is almost a pure standing wave, so the minimum stratification occurs close to high water. In the case of the Rhine ROFI, the tides behave more like a Kelvin wave, i.e. the maximum alongshore velocity coincides with high water. The modification in the tidal currents caused by the presence of stratification generates a cross-shore shear, in such a way that the maximum and minimum stability coincides with high and low water respectively. This is because the maximum cross-shore velocities are at about $90^{\circ}$ out of phase with the alongshore velocities and elevation, while bottom and surface cross-shore currents are in opposing directions, as observed in previous data (e.g. Visser et al., 1994), in such a way that the maximum shear is observed a quarter of tidal cycle after maximum flood and after maximum ebb. Thus, when you integrate in time to find the maximum cross-shore differential tidal displacement, it will be in phase with the alongshore velocities and the surface elevation.

In such a variable environment it is very difficult to make synoptic observations of the density structure. The closest we can get to it with the technology available is by using an 

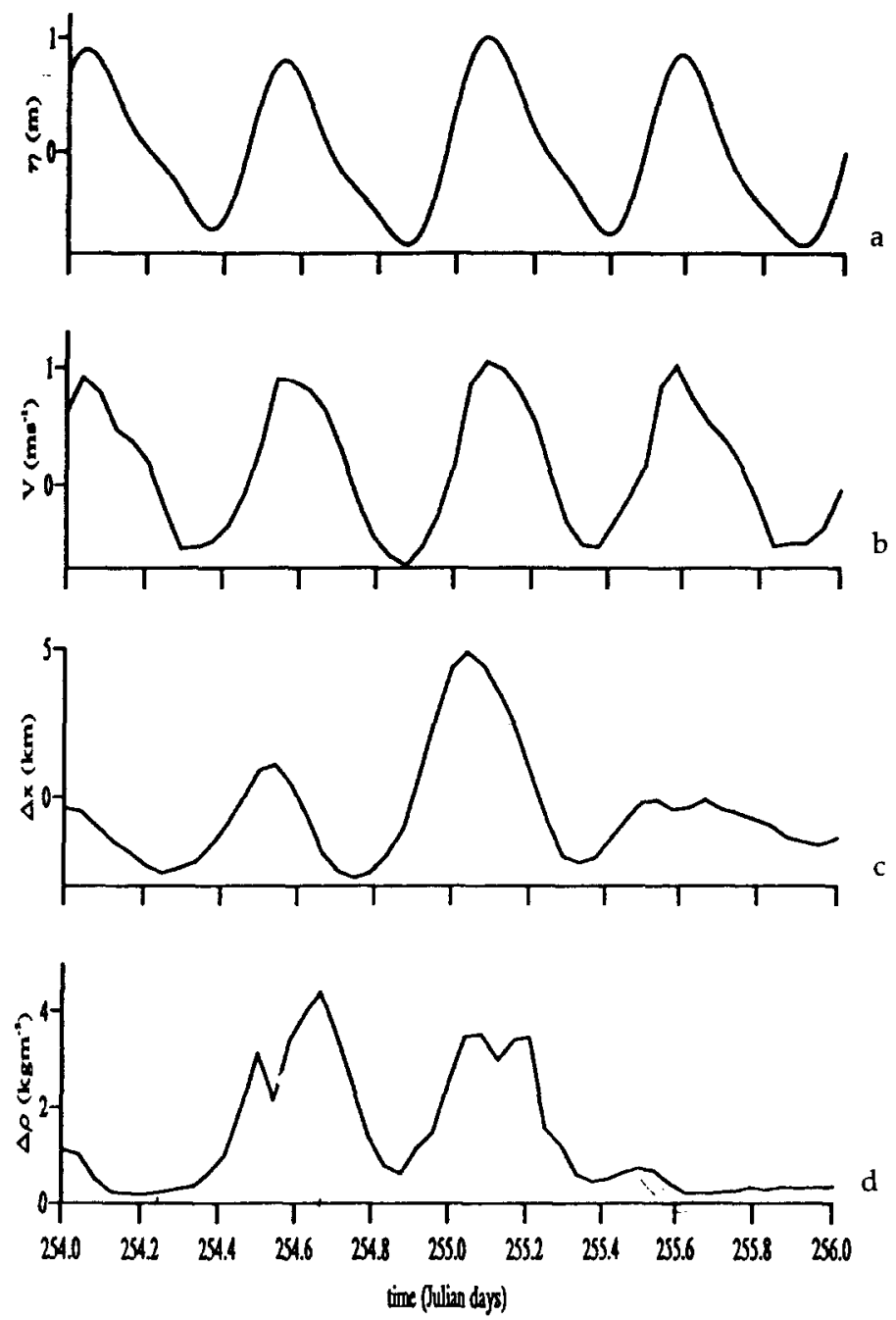

Fig. 2. Time-series at mooring A. Showing (a) tidal elevation; (b) alongshore velocity; (c) bottom-surface differential displacement, positive offshore; and (d) stratification as bottomsurface density difference.

undulator which allowed us to monitor a $25 \mathrm{~km}$ long cross-shore section every hour and a half. The observations undertaken show a strong coherence with the time series at the mooring (Fig. 3); during the turn from high to low water the stratification starts to decrease [Fig. 3(a)], and is further reduced at low water [Fig. 3(b)]. The stability then starts to increase as the tide rises [Fig. 3(c)], reaching a maximum near high water [Fig. 3(d)]. This cycle shown in Fig. 3 will repeat every tidal period as long as the stirring conditions are low enough to permit stratification to develop.

\section{INTERPRETATION}

Let us consider a period of complete vertical mixing, when we have a vertically homogeneous cross-shore density [Fig 4(a)] and the tidal ellipses are almost degenerate, 

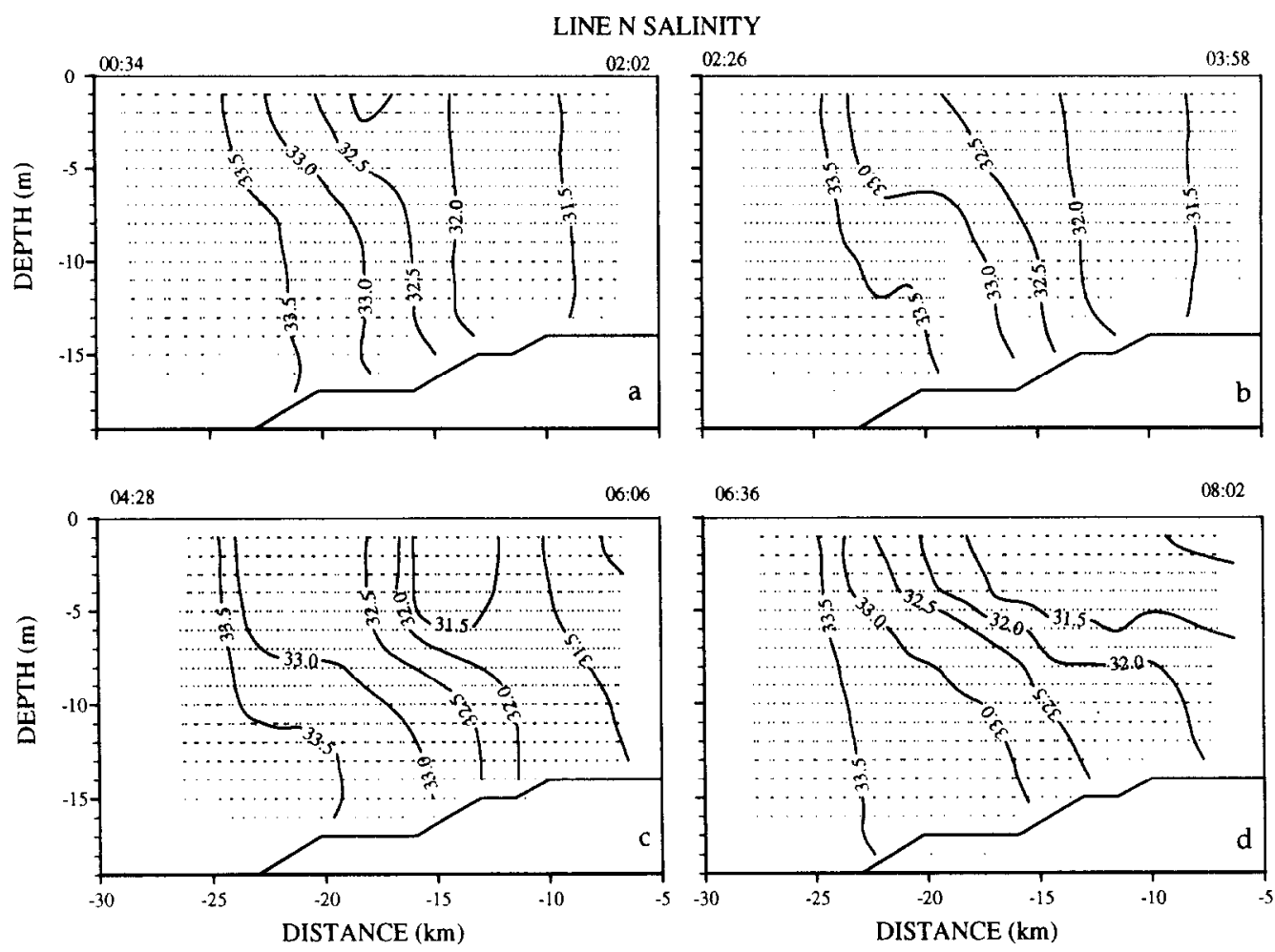

Fig. 3. Salinity sections from SEAROVER on 17 September 1992 (a) approximately $3 \mathrm{~h}$ after high water; (b) at low water; (c) $3 \mathrm{~h}$ after low water; (d) at high water. The starting and end times are shown on top of each section and the position of the original data is shown by dots.

particularly at the surface. If the stirring decreases, the density gradients start to relax as in the Linden and Simpson (1988) laboratory experiments, but the spreading will be limited by the effect of the Earth's rotation as in the two-layer model of Ou (1983). The presence of stratification decouples the bottom and surface layers, which modifies the tidal ellipses, creating more circular ellipses at bottom and surface, which rotate in different directions [Fig. 4(b)], i.e. clockwise at the surface, anticlockwise at the bottom (Visser et al., 1994; Souza and Simpson, 1995). This modification of the tidal ellipses will generate a strong cross-shore tidal shear, which then interacts with the cross-shore density gradients. This will make the system fluctuate between periods of strong stability at high water [Fig. 4(b)] and periods of water column homogeneity at low water (Fig. 4(c)].

\section{THE MODEL}

The model is a two-dimensional version of a three-dimensional model based on that of James (1986) but with several changes, particularly to the time differencing, which now uses forward time stepping, and to the advection scheme, described in more detail below. The separation into barotropic and baroclinic parts is also different: here, it is the depth- 

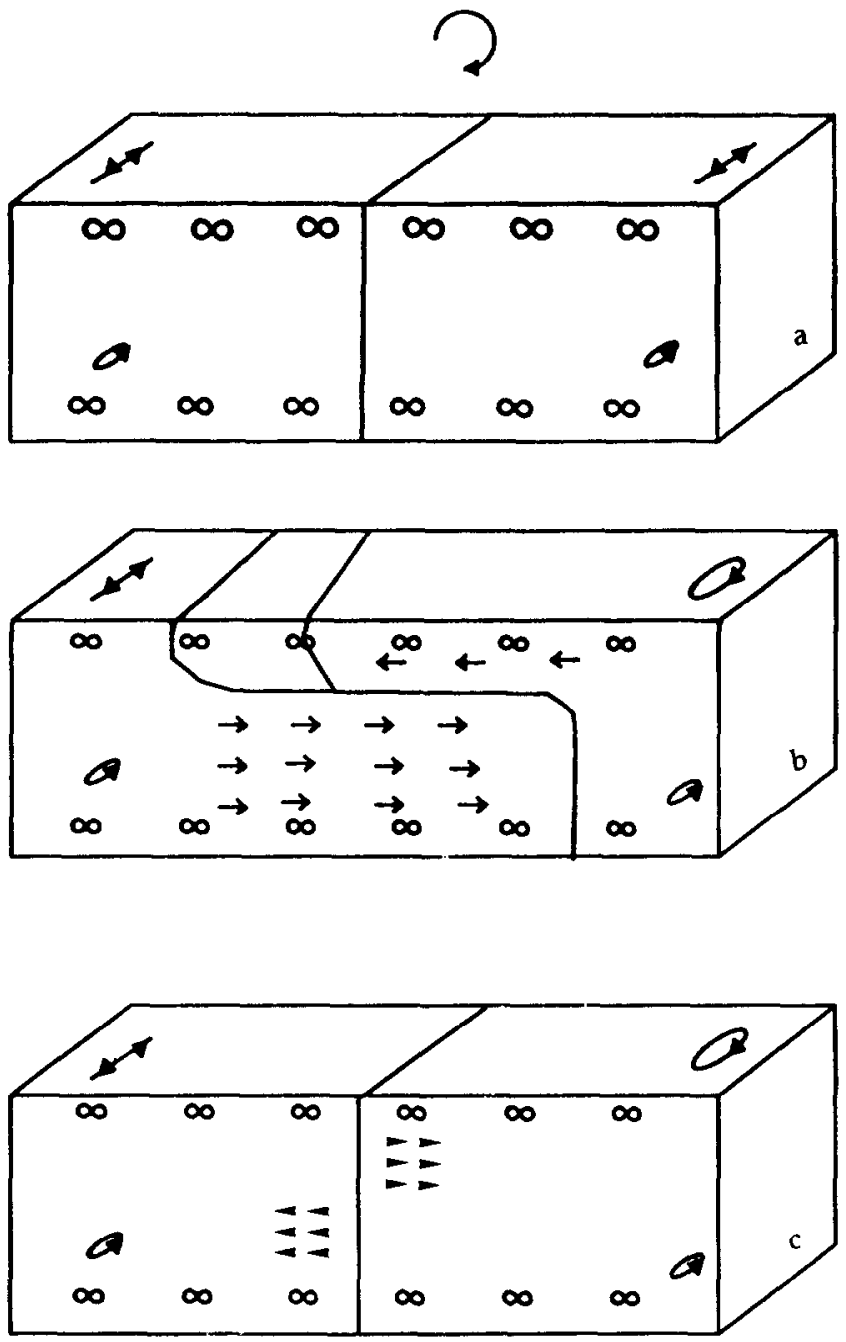

Fig. 4. Schematic of processes in the Rhine ROFI (a) shows the homogeneous water column and the tidal ellipses at a period of high tidal and wind stirring; (b) shows the ROFI system when stirring has diminished. The density gradients relax and modify the tidal ellipses, generating strong crossshore tidal shear, which will interact with the cross-shore density gradients, enhancing stratification at high water when the differential displacement is offshore; (c) the ROFI is under the same conditions as (b), but at low water when the differential displacement is onshore, so the straining interaction with the density gradients brings the water column to complete or almost complete mixing. Whenever the stirring is low, the system will be fluctuating between $b$ and $c$ in the tidal cycle, bringing semi-diurnal variahility in stratification.

mean velocities which are calculated with the shorter barotropic time step. The sigma coordinate grid is retained in the vertical, so that

$$
\sigma=(z-\zeta) / H,
$$

where $\zeta(x, y, t)$ is the surface elevation and $H=h+\zeta$ is the total depth, with $z=-h(x)$ the sea bed and so $\sigma=0$ at the surface, -1 at the sea bed. In the sigma coordinate 


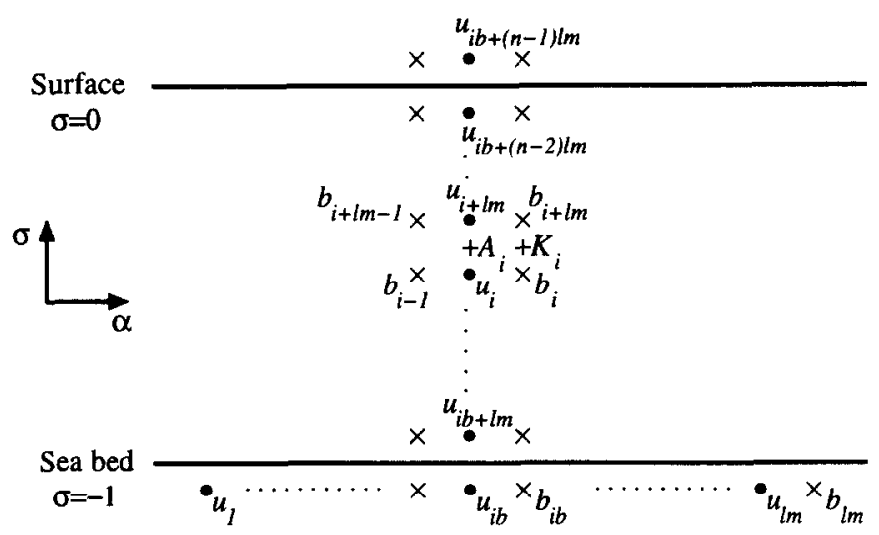

Fig. 5. The model grid.

transformation $(x, y, z, t)$ coordinates are transformed to $(\alpha, \beta, \sigma, \tau)$ coordinates, with $\alpha=x$, $\beta=y$ and $\tau=t$. In the two-dimensional version, although some variables such as the bathymetry are supposed to have no variation in the $y$, or alongshore, direction, others such as elevation are allowed to vary with $y$, so that for example a Kelvin wave can be imposed travelling alongshore.

In two dimensions $(\alpha-\sigma)$, the B grid used by James (1986) collapses as shown in Fig. 5 so that scalar values such as salinity, temperature and buoyancy, shown as $b$ points in the figure, lie in the same vertical plane as velocity points, shown as $u$ points, and on the same $\sigma$ levels. Surface elevation is defined at the horizontal position of $b$ columns. Points are numbered up to $l m$ in the horizontal (to agree with the three-dimensional numbering scheme) and $n$ in the vertical. The variables are written as long vectors with dimension I $m \times n$.

The incompressible, Boussinesq, hydrostatic equations to be solved in sigma coordinates are as follows, firstly for the depth mean velocity $(\bar{u}, \bar{v})$ :

$$
\begin{gathered}
\partial \bar{u} / \partial \tau=f \bar{v}-g \partial \zeta / \partial \alpha+\left(F_{S}-F_{B}\right) / H+N L B_{\alpha} \\
\partial \bar{v} / \partial \tau=-f \bar{u}-g \partial \zeta / \partial \beta+\left(G_{S}-G_{B}\right) / H+N L B_{\beta} \\
\partial \zeta / \partial \tau=-\partial(H \tilde{u}) / \partial \alpha-\partial(H \bar{v}) / \partial \beta,
\end{gathered}
$$

where $F_{S}, F_{B}, G_{S}, G_{B}$ are components of surface and bottom stress and $N L B_{\alpha}, N L B_{\beta}$ are depth means of the nonlinear and buoyancy terms in the following equations for velocity deviations $u_{r}=u-\bar{u}, v_{r}=v-\bar{v}$ :

$$
\begin{aligned}
\partial u_{r} / \partial \tau= & -L(u)+f v_{r}-\partial\left(H \int_{0}^{\sigma} b \mathrm{~d} \sigma\right) / \partial \alpha \\
+(\partial \zeta / \partial \alpha+ & \sigma \partial H / \partial \alpha) \cdot b+\left(1 / H^{2}\right) \partial(A \partial u / \partial \sigma) / \partial \sigma \\
& -\left(F_{S}-F_{b}\right) / H-N L B_{\alpha} \\
\partial v_{r} / \partial \tau= & -L(v)-f u_{r}-\partial\left(H \int_{0}^{\sigma} b \mathrm{~d} \sigma\right) / \partial \beta
\end{aligned}
$$




$$
\begin{gathered}
+(\partial \zeta / \partial \beta+\sigma \partial H / \partial \beta) \cdot b+\left(1 / H^{2}\right) \partial(A \partial v / \partial \sigma) / \partial \sigma \\
-\left(G_{S}-G_{B}\right) / H-N L B_{\beta} .
\end{gathered}
$$

Also the salinity $S$ is given by

$$
\partial S / \partial \tau=-L(S)+\left(1 / H^{2}\right) \partial(K \partial S / \partial \sigma) / \partial \sigma,
$$

with a similar equation for temperature, where

$$
L=u \partial / \partial \alpha+v \partial / \partial \beta+\Omega \partial / \partial \sigma
$$

is the advection term (see below), with

$$
\Omega=-(\sigma / H) \partial \zeta / \partial \tau-(1 / H)\left[\partial\left(H \int_{0}^{\sigma} u \mathrm{~d} \sigma\right) / \partial \alpha+\partial\left(H \int_{0}^{\sigma} v \mathrm{~d} \sigma\right) / \partial \beta\right]
$$

and buoyancy $b=g\left(\rho_{0}-\rho\right) / \rho_{0}$, with $\rho_{0}$ a reference density.

The eddy viscosity $A$ and diffusivity $K$, defined on points in velocity and scalar vertical columns respectively with $\sigma$-values between those of the velocity and scalar variables as shown in Fig. 5, are given by a simple Richardson number formulation. A mixing length $l$ is assumed to be a fraction of the depth [following Csanady (1976)], here $0.05 H$, and the Richardson number is defined as

$$
R i=\partial b / \partial z /\left((\partial u / \partial z)^{2}+(\partial v / \partial z)^{2}\right) .
$$

A basic value of $A$ or $K$ resulting from surface or bed stress is assumed to be given by $u_{*} l$, where $u_{*}$ is the appropriate friction velocity. Then this is reduced linearly with $R i$ until a cut-off value (here $R i=0.23$ ) is reached. Hence, for the bed stress contribution to $A$,

$$
\begin{array}{rlrl}
A\left(z_{1}\right) & =\min _{z \leqslant z_{1}}\left(A_{1}(z)\right), \text { where } & & \\
\mathrm{A}_{1}(z) & =u_{*} \ell(0.23-R i) / 0.23 & \text { for } \quad 0 \leqslant R i<0.23 \\
& =0 & \text { for } \quad R i \geqslant 0.23,
\end{array}
$$

with a similar expression for the surface stress contribution, which decreases monotonically from the surface downwards. The contributions from surface and bed stress are then added together. If $\partial b / \partial z<0$, mixing is assumed to be instantaneous until stable stratification is produced. In practice, a small minimum value of $0.002 \mathrm{~m}^{2} \mathrm{~s}^{-1}$ is assumed for the $u_{*} l$ due to surface stress, and a minimum value for $A$ and $K$ of $10^{-4} \mathrm{~m}^{2} \mathrm{~s}^{-1}$ is taken, to help produce realistic results in the case of surface heating. However, heating is not considered here. In fact, the present model will run stably with zero friction, that is with zero $A, K$ and bottom friction coefficient. Here, $F_{B}, G_{B}$ and the sea-bed value of $u_{*}$ are calculated assuming quadratic bottom friction with a coefficient of 0.005 .

This simple Richardson number formulation is an alternative to more computationally intensive turbulent energy schemes. It reproduces the main features of stratified shelf seas, namely a wind-mixed upper layer and tidally mixed lower layer with a region of low viscosity and diffusivity in the thermocline. It has been successful, in the three-dimensional version of the model, in predicting the distribution of well-mixed and stratified areas in summer in the southern North Sea (Huthnance et al., 1993).

The advection scheme used here is the TVD scheme of James (1995). This uses a 
combination of upwind (UP) and Lax-Wendroff (LW) schemes, in a similar way to the hybrid scheme of James (1986), but with a different switch factor, or limiter function $\phi(r)$ :

$$
\begin{aligned}
& \text { the total flux } F_{i+1 / 2}=F_{i+1 / 2}^{\mathrm{UP}}+\phi(r) F_{i+1 / 2}^{\mathrm{LMU}}, \\
& \text { where } F_{i+1 / 2}^{\mathrm{LMU}}=F_{i+1 / 2}^{\mathrm{LW}}-F_{i+1 / 2}^{\mathrm{UP}} \\
& \text { and } r=F_{i+1 / 2-s}^{\mathrm{LMU}} / F_{i+1 / 2}^{\mathrm{LMU}}, \\
& \text { where } s=\operatorname{sign}\left(u_{i+1 / 2}\right),
\end{aligned}
$$

where $u_{i+1 / 2}$ is the relevant advecting velocity.

Several limiter functions have the TVD (total-variation-diminishing) property such that unphysical ripples are not produced in the solution, but sharp gradients in the advected quantity are retained (Yang and Przekwas, 1992). The one used here is "superbee":

$$
\phi(r)=\max (0, \min (2 r, 1), \min (r, 2)) .
$$

The advective part of the solution is directionally split, so that the $\alpha$-direction advection is done first and then adjustment in the vertical direction follows. The volume fluxes in the $\alpha$ direction imply relative changes in the sigma levels of the top and bottom of the grid boxes in each vertical column. The vertical adjustment consists of calculating the vertical fluxes of the variable involved in returning these sigma levels to the original distribution. This is done using the same TVD scheme and is equivalent to the vertical $\Omega$ advection term in equation (8). However, the formulation in terms of fluxes and finite grid box volumes is more satisfactory numerically. In the case of three dimensions, this vertical adjustment is followed by an advection in the $\beta$ direction followed by a further vertical adjustment.

The use of an advanced advection scheme which has low numerical diffusion is critical to the success of the model in reproducing the process of tidal straining, since the front at the edge of the Rhine plume must be advected backwards and forwards by the tidal current without being diffused away. Stratification must be reformed on each tide so as to affect the vertical eddy viscosity, which in turn produces the tidal current shear which causes tidal straining, so the process is strongly non-linear.

The vertical mixing terms are solved using the Crank-Nicholson scheme so that they do not limit the time step, and a semi-implicit form of bottom friction is used for stability. The barotropic equations (2)-(4) are solved by the forward-backward time, centred space scheme (Mesinger and Arakawa, 1976), in which updated velocities are used at each stage. Open boundary conditions are applied to the surface elevation and salinity in a four-pointwide relaxation zone (James, 1990), where values of elevation are made to tend towards the imposed tidal elevation and salinity is made to tend towards the offshore value. The velocity is linearized in the column next to the open boundary; in other words, advection of velocity is not applied there.

In the results shown here, a rcgion cxtcnding $30 \mathrm{~km}$ offshore and $20 \mathrm{~m}$ deep is considered, with a vertical wall at the nearshore end. The grid size is $1 \mathrm{~km}$ in the horizontal, and there are 20 points in the vertical. A Kelvin wave with semi-diurnal frequency and coastal amplitude $1 \mathrm{~m}$ (which is comparable to the elevation amplitude from observations) is imposed, by specifying elevation at the offshore boundary, the alongshore elevation gradient $\partial \xi / \partial \beta$ and the alongshore transport gradient $\partial(H \bar{v}) / \partial \beta$. All other longshore gradients are assumed to be zero. The initial salinity is assumed to be vertically well mixed, with a value of $28 \mathrm{psu}$ at the coast and $34 \mathrm{psu}$ at $13 \mathrm{~km}$ offshore [Fig. 6(a)]. The 
initial elevation and current is that of the Kelvin wave plus that due to a density-driven flow in geostrophic balance assuming zero geostrophic flow at the sea bed [Fig. 6(b)]. The simulation has a constant wind speed of $7 \mathrm{~m} \mathrm{~s}^{-1}$ and the wind direction varies randomly. The solution is then stepped forward with a time step of $30 \mathrm{~s}$ for the barotropic terms and $120 \mathrm{~s}$ for the rest. After $24 \mathrm{~h}$ from the start, a tidal cycle is achieved which is matched closely by the previous cycle, so that this may be taken as a typical simulated tidal period.

\section{MODEL RESULTS}

Preliminary simulations suggest that the tidal energy alone is not sufficient to suppress stratification when using realistic elevation amplitudes for spring tides. The presence of strong wind stirring is necessary to mix the water column, as observed in the data (Simpson and Souza, 1995).

Figure 7 shows a series of salinity sections from the model: at $27 \mathrm{~h}$ [Fig. 7(a)], $3 \mathrm{~h}$ after high water, the water column shows moderate stratification; at low water [Fig. $7(\mathrm{~b})]$ the water column has become more vertically homogeneous. But a quarter of a tidal cycle later, the water column starts to re-stratify [Fig. 7(c)], reaching its maximum at high water [Fig. 7(d)], showing strong coherence with the SEAROVER observations shown in Fig. 3.

The current distribution associated with the above density structure is observed in Fig. 8 . The velocity distributions show that both the along and cross-shore velocities have a maximum inside the stratified area, bounded at approximately $10 \mathrm{~km}$. This stratified region shows a strong cross-shore shear, which is not apparent in the mixed region. The cross-shore shear is maximum when the tidal elevation is equal to that of the mean sea level, while the maximum velocities are at high and low water.

In Fig. 9, we observe the relation between straining and the propagation of the tidal wave from the simulation at location $15 \mathrm{~km}$. These results are in good qualitative agreement with the mooring data (Fig. 2), with the elevation, the alongshore velocity, the cross-shore relative displacement and the stratification all in phase and of similar magnitude as the observations.

Simulation using strong winds $\left(20 \mathrm{~m} \mathrm{~s}^{-1}\right.$ northward or $25 \mathrm{~m} \mathrm{~s}^{-1}$ southward) maintains almost complete water column homogeneity throughout the simulation and does not show any evidence of the strong cross-shore shear, even $3 \mathrm{~h}$ after low water when under stratified conditions this shear is a maximum (Fig. 10).

The wind direction is also an important factor affecting the stratification (Munchow and Garvine, 1993), as observed in Table 1 where we show model simulations using a wind speed of $7 \mathrm{~m} \mathrm{~s}^{-1}$ and different wind direction. The upwelling and offshore winds favour the

Table 1. Mean stratification against wind direction, with a constant wind speed of $7 \mathrm{~m} \mathrm{~s}^{-1}$

\begin{tabular}{ll}
$\begin{array}{l}\text { Stratification } \\
\text { (psu) }\end{array}$ & \multicolumn{1}{c}{ Direction } \\
\hline 0.66 & $\begin{array}{l}\text { North- } \\
\text { downwelling }\end{array}$ \\
5.70 & West-offshore \\
5.92 & South-upwelling \\
0.65 & East-onshore \\
\hline
\end{tabular}


m

\section{0 hours}

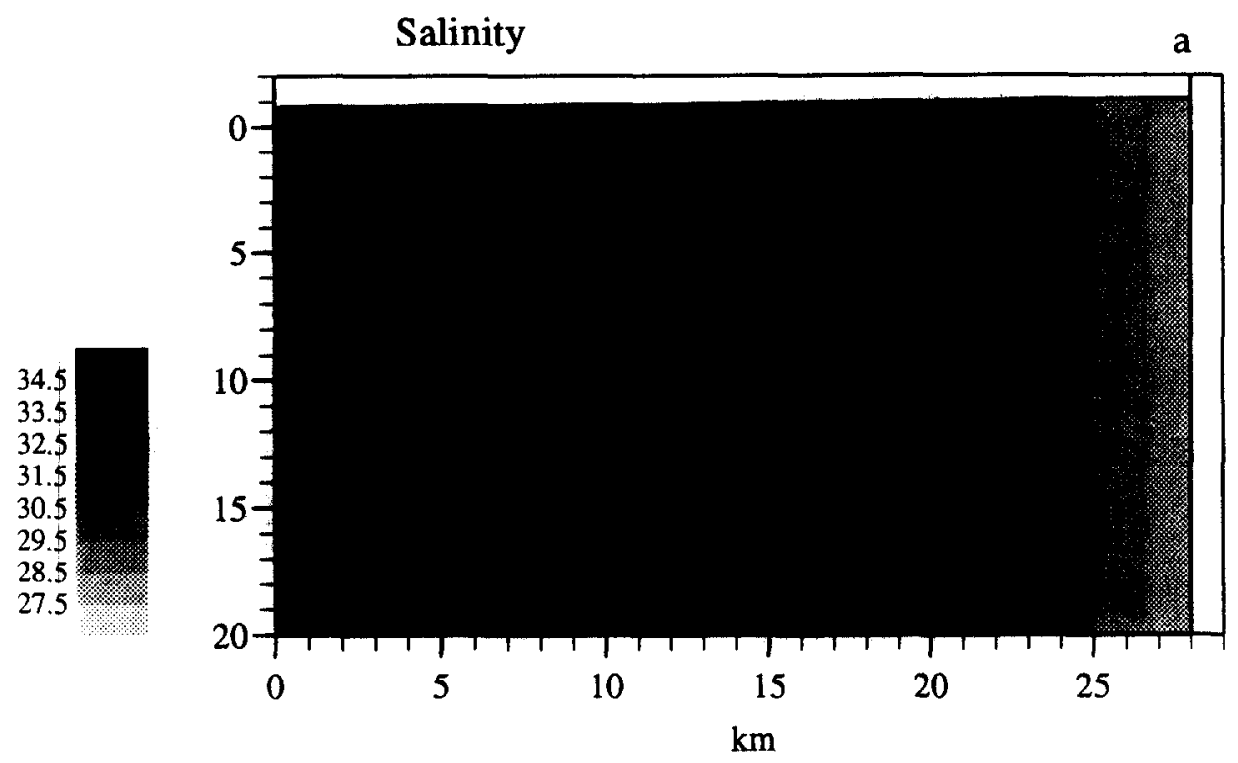

m

Velocity: $\mathrm{v}$ contours, $\mathrm{u}, \mathrm{w}$ vectors

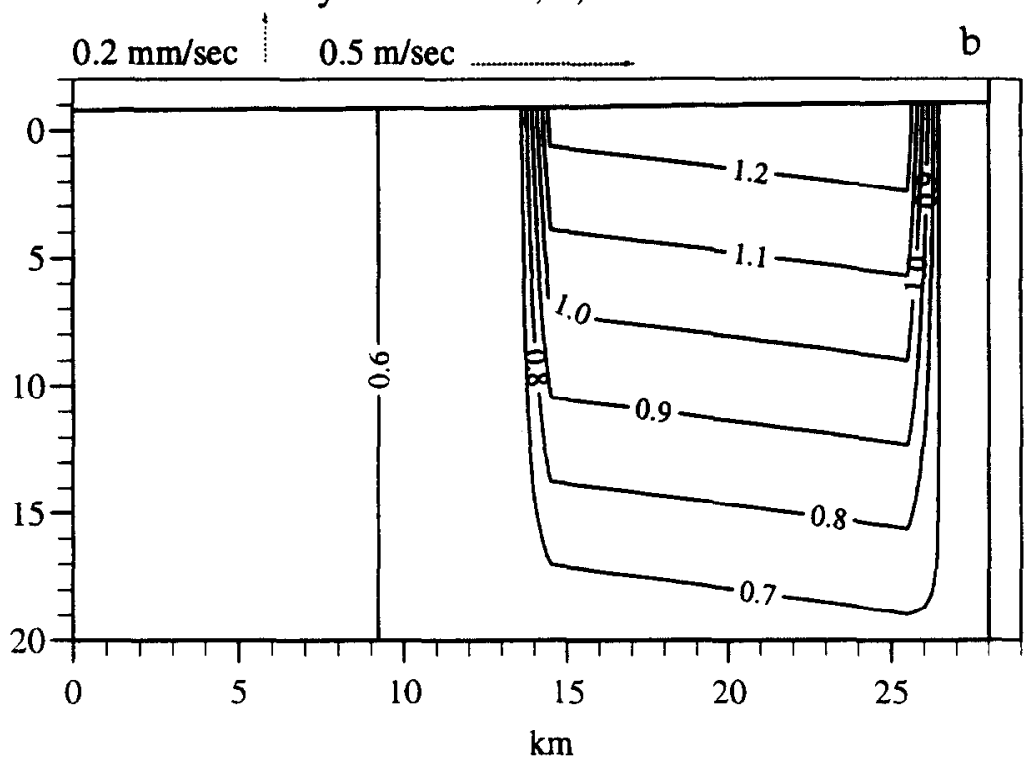

Fig. 6. Slice model initial conditions (a) the original salinity structure; (b) the initial flow. 
A. J. Souza and I. D. James
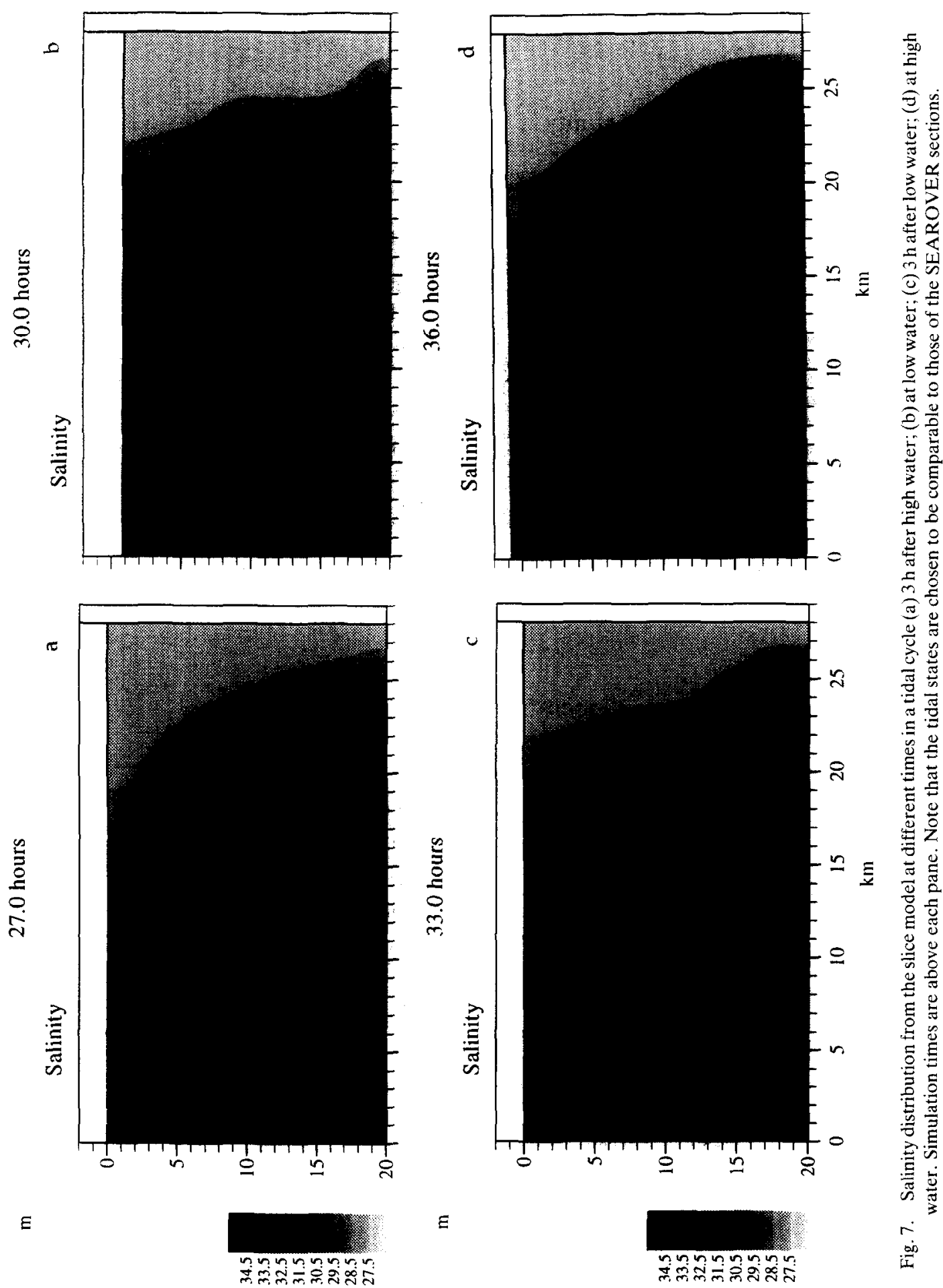

$E$
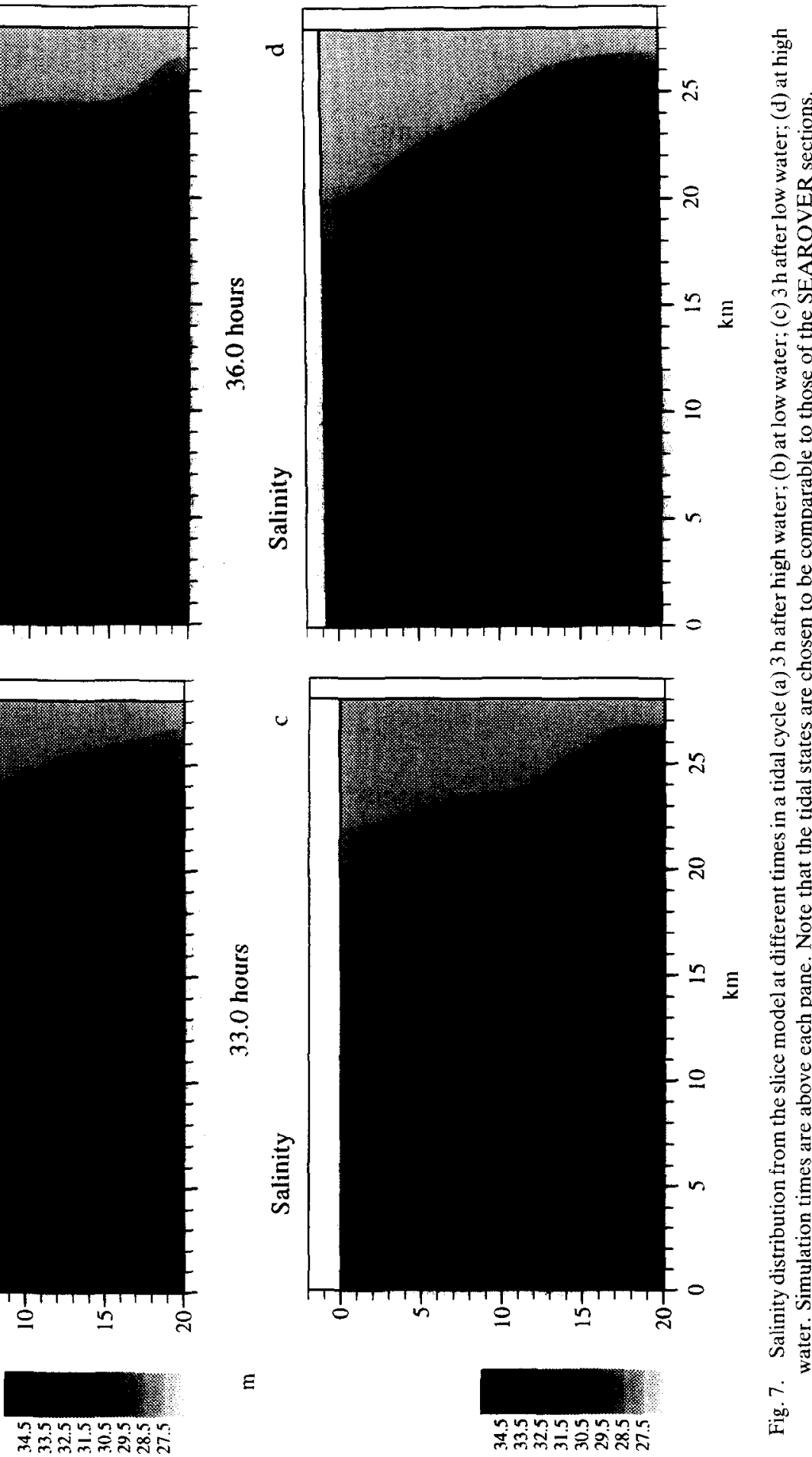

学

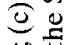

这菩

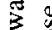

栗

岁

要

$\frac{\pi}{\mathbb{T}}$

造

䒕

5

$\stackrel{0}{0}$ 

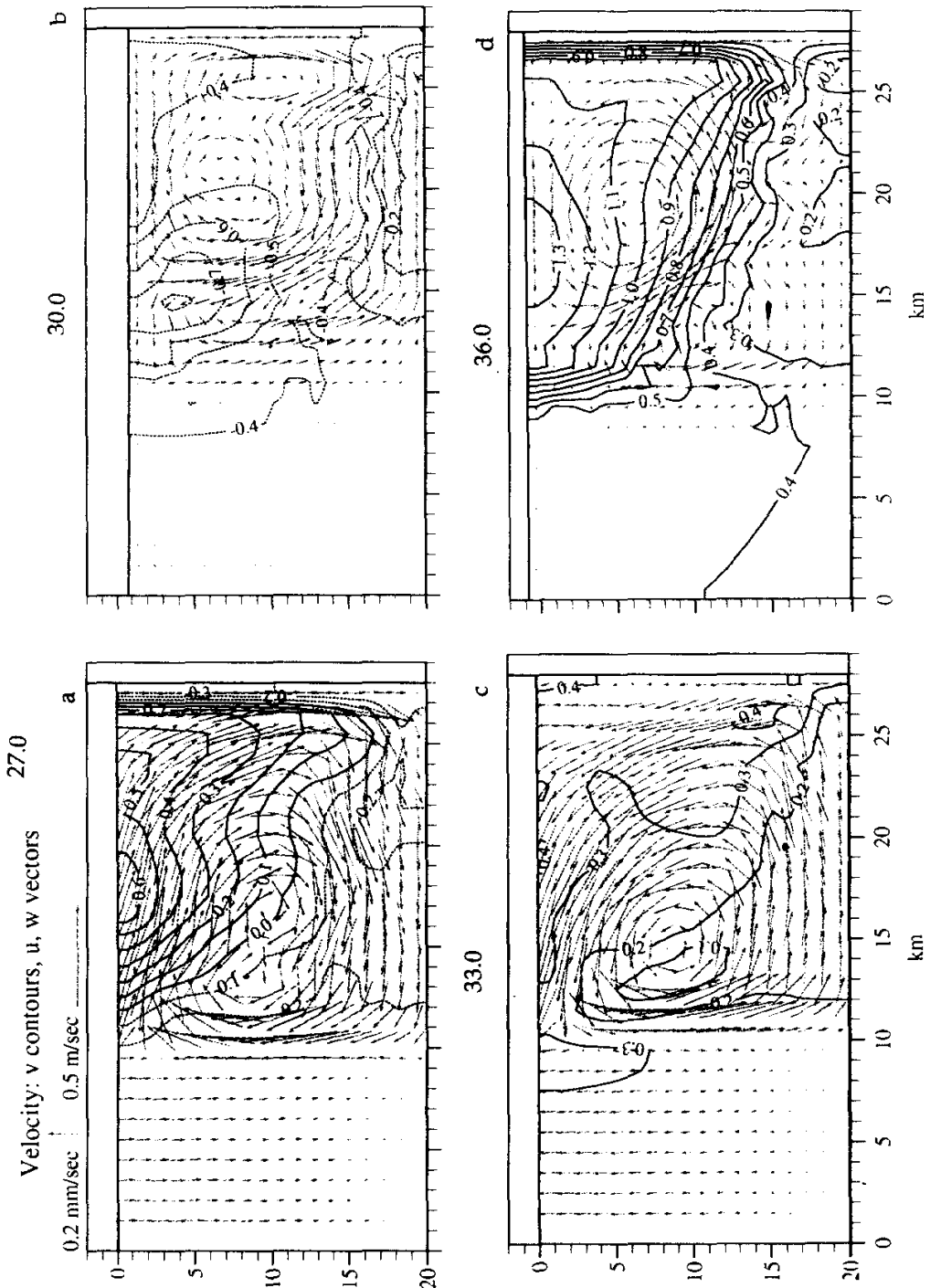

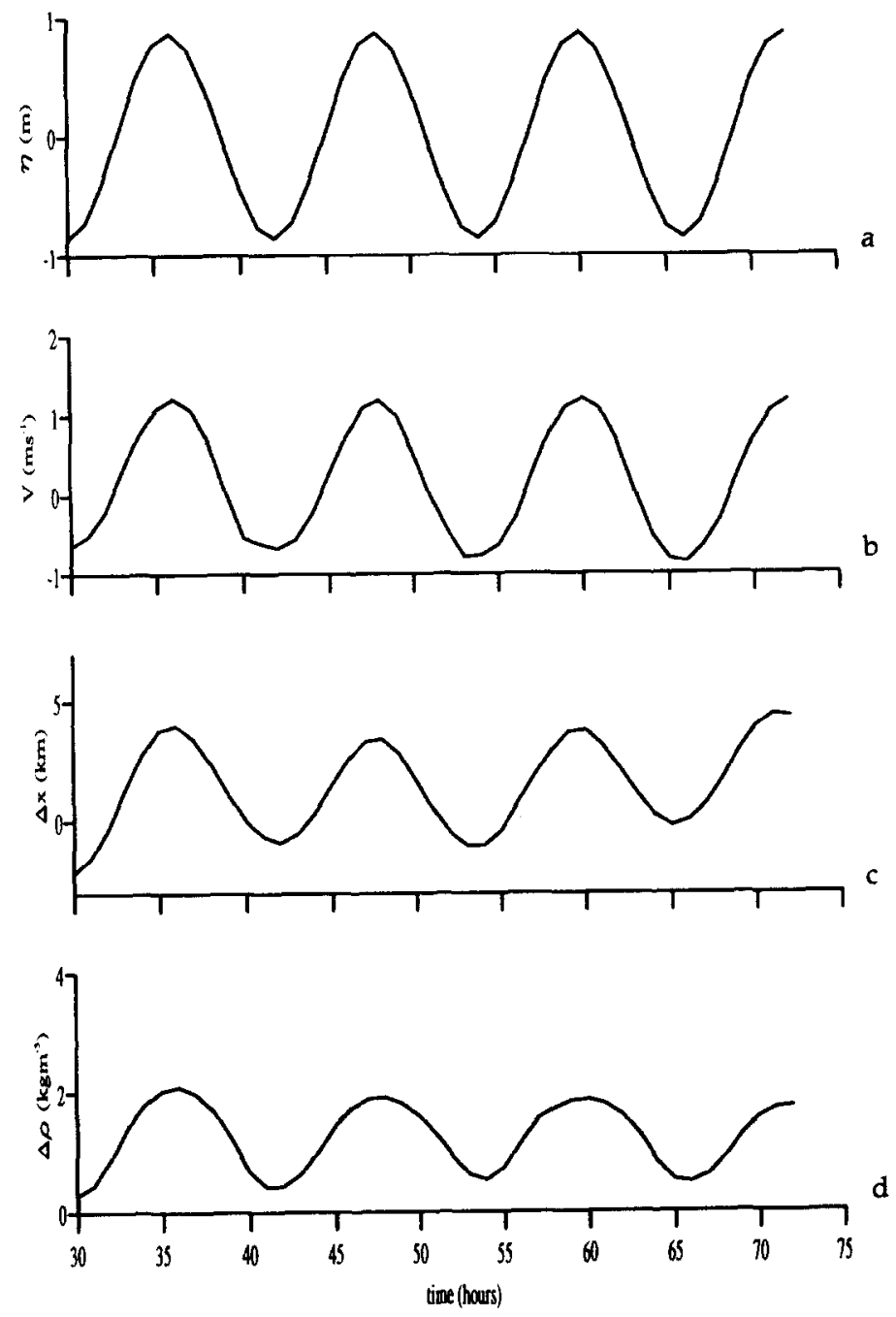

Fig. 9. Same as Fig. 2 but from model simulations at a location $15 \mathrm{~km}$ from the open boundary.

presence of stratification, while downwelling and onshore winds favour homogeneity. Another example of the effect of the wind directionality on stratification is that to mix the water column using a purely southward wind, a speed of $25 \mathrm{~m} \mathrm{~s}^{-1}$ is needed [Fig. 10 (c),(d)], compared to the $20 \mathrm{~m} \mathrm{~s}^{-1}$ needed using a purely northward wind [Fig. 10(a),(b)]. The effect of upwelling or downwelling winds on stratification observed here is possible due to the fact that the Ekman number is approximately 0.4 , so that the effect of Coriolis is appreciable.

\section{DISCUSSION AND CONCLUSION}

The idea of the presence of stratification as the driving mechanism for cross-shore shear (Souza and Simpson, 1994) is evident in Fig. 8 where there is no cross-shore transport 
m

33.0 hours

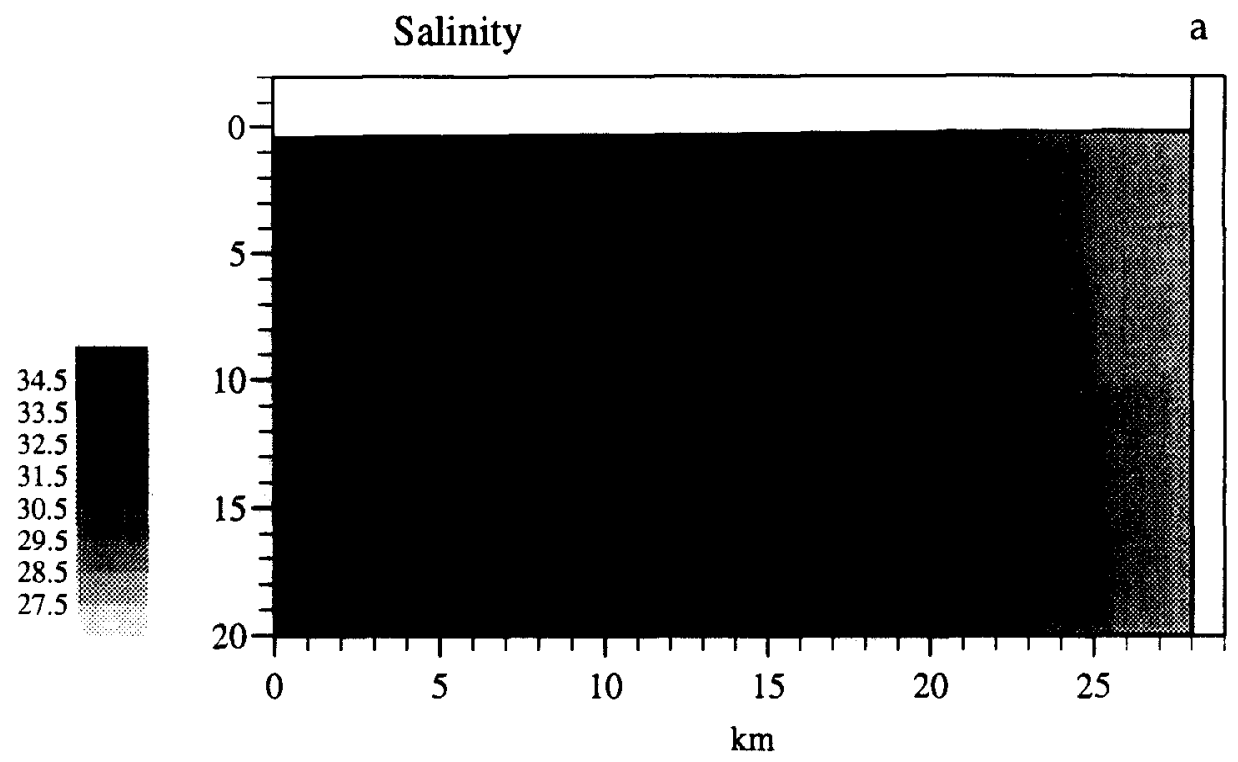

m

Velocity: $\mathrm{v}$ contours, $\mathrm{u}, \mathrm{w}$ vectors

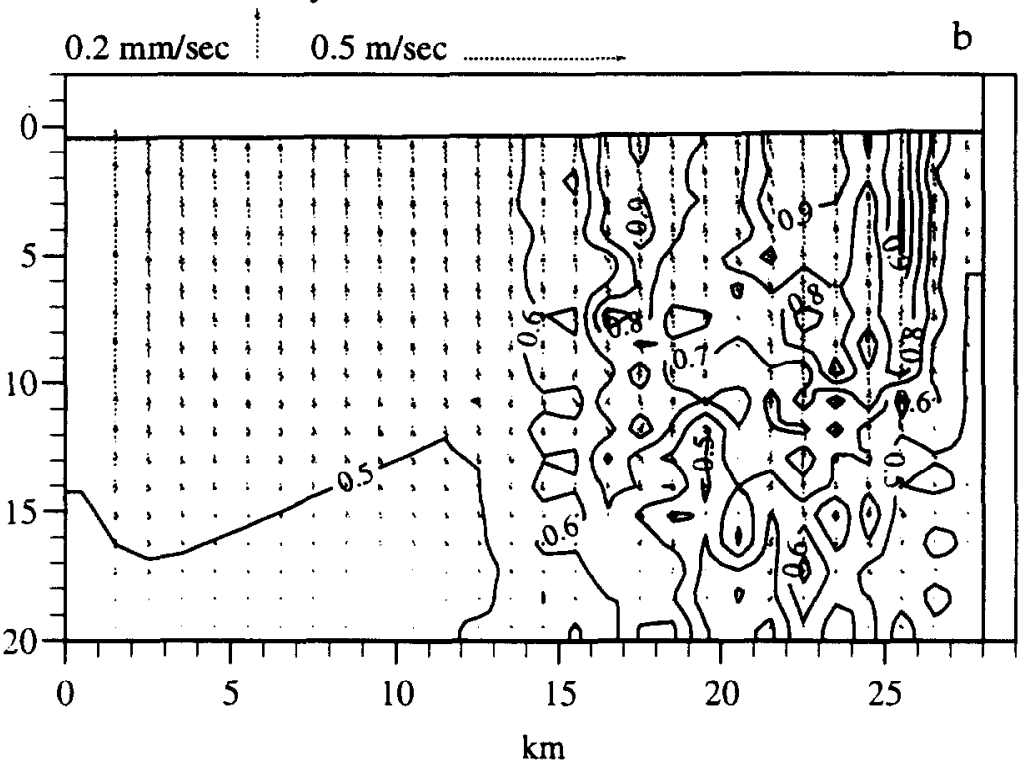

Fig. 10. Density and flow structure from the model using a northward wind forcing of $20 \mathrm{~m} \mathrm{~s}^{-1}$ [(a)(b)] and southward wind forcing [(c)(d)] of $25 \mathrm{~m} \mathrm{~s}^{-1}$. 
m

\section{0 hours}

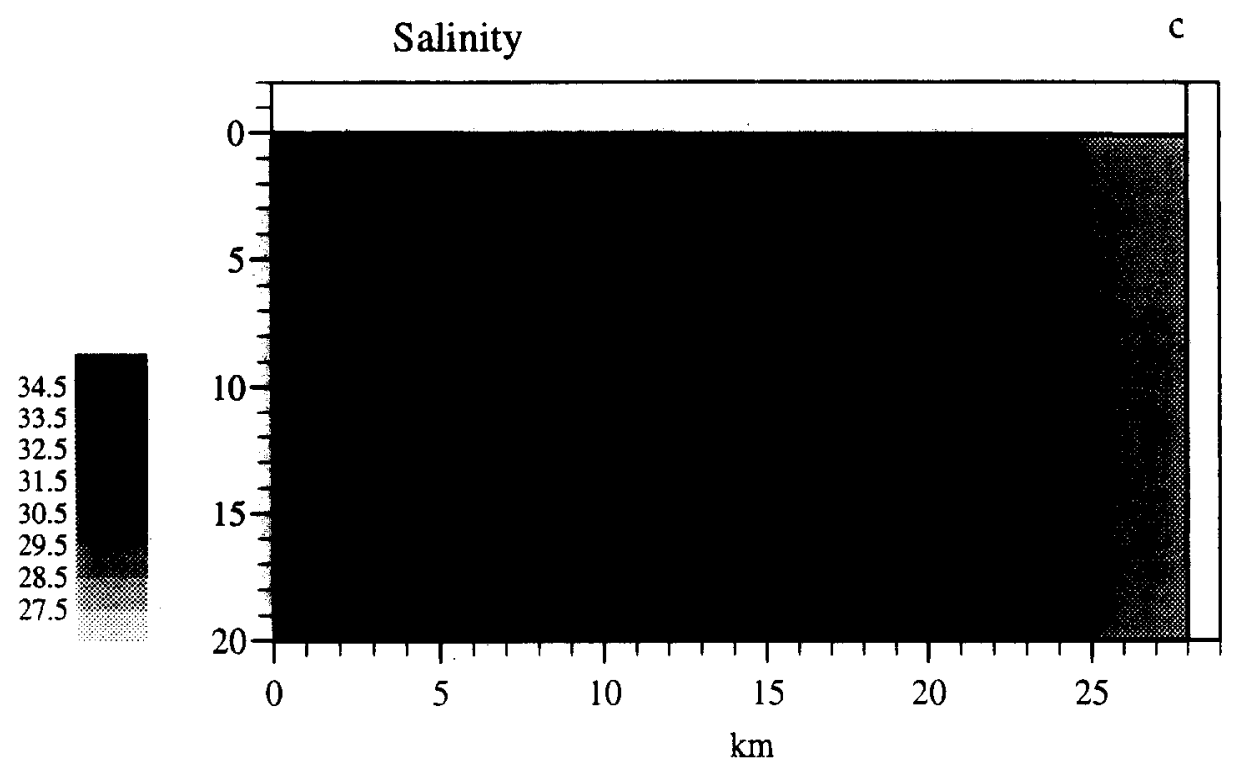

m

Velocity: v contours, $\mathrm{u}, \mathrm{w}$ vectors

$\mathrm{d}$

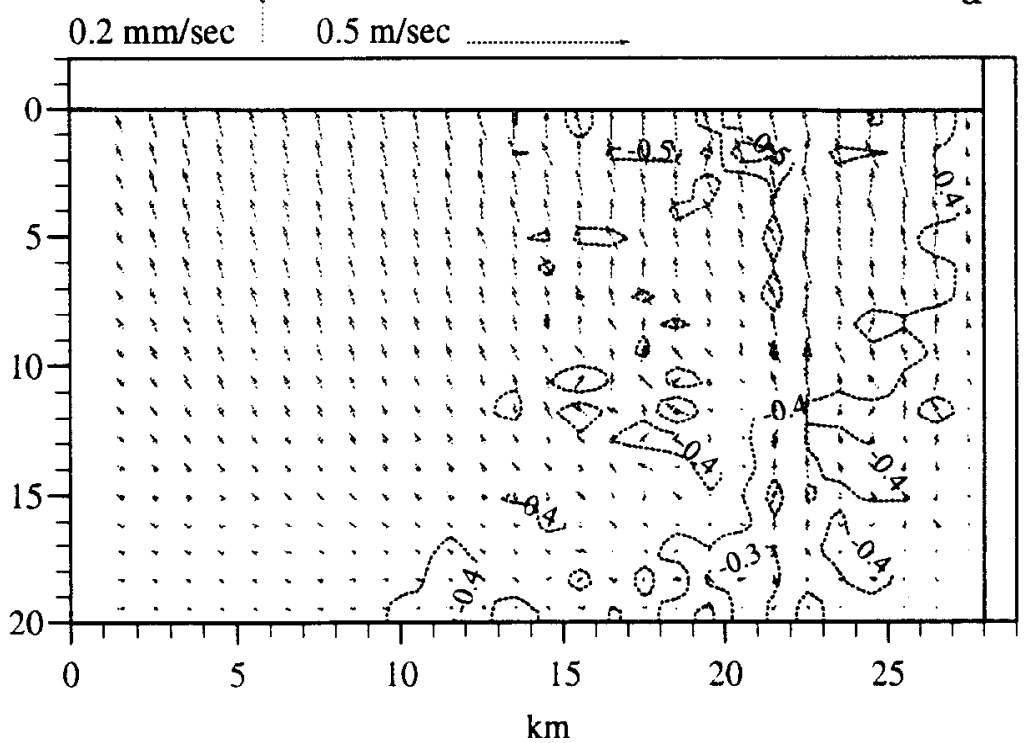

Fig. 10. (Continued.) 
Tidal average eddy viscosity

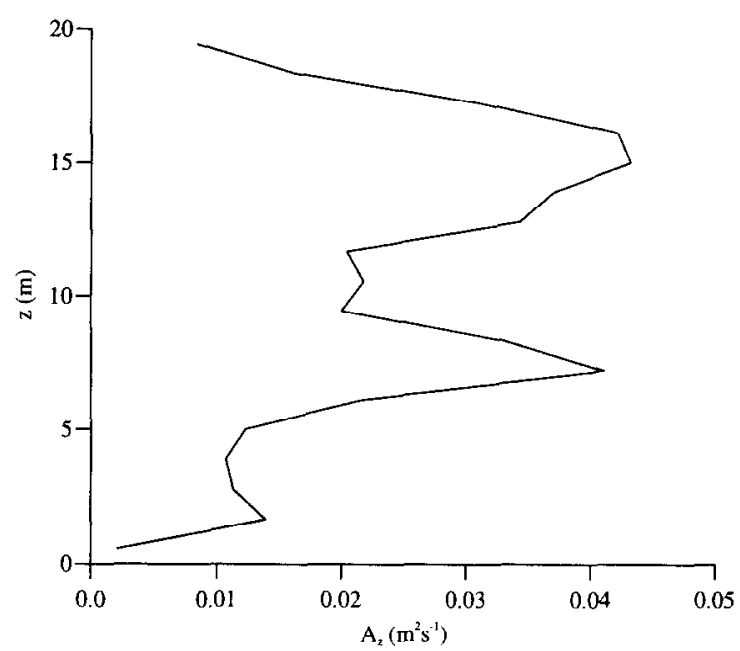

Fig. 11. Vertical profile of eddy viscosity from the model, averaged over a tidal cycle.

outside the stratified area or in the simulations where the water column is maintained homogeneous (Fig. 10). This strong cross-shore tidal shear results from the modification of the tidal ellipses by the presence of stratification (Visser et al., 1994; Souza and Simpson, 1994), in which a reduction of the eddy viscosity near the pycnocline (Fig. 11) decouples the bottom and surface layer, polarizing the tidal ellipses which will be more clockwise towards the surface and anti-clockwise towards the bottom.

The strong cross-shore tidal shear discussed above is the mechanism responsible for the generation of the semi-diurnal variability of stratification. From Figs 7, 8 and 9, we can observe how the maximum in stratification always coincides with the maximum bottomsurface relative displacement ( $3 \mathrm{~h}$ after the maximum shear); this is because the vertical mixing frequency $\left(K / H^{2}\right)$ is approximately six times smaller than the tidal frequency. The way in which this strong tidal straining generates such strong semi-diurnal fluctuations in stability is by interacting with the cross-shore density gradients.

The strong interaction between stratification, strong minor axis straining and hence strong semi-diurnal variability in stratification appears to be universal for the case when the major axis is oriented orthogonal to the density gradient. This is in contrast to the case when the major axis and the density gradient are aligned, as in the case of Liverpool Bay (Sharples and Simpson, 1994), where although the stratification enhances the minor axis shear it is orthogonal to the density gradient; hence little enhancement of the semi-diurnal stratification will be observed.

The model confirms that the wind is the dominant stirring process in the Rhine ROFI. It also confirms the ideas of Munchow and Garvine (1983), who suggest the importance of the wind direction in enhancing or suppressing stratification; i.e. upwelling wind enhances stratification while downwelling favours mixing. 
Acknowledgements - This study was supported by the EEC through the Mast program under the MAS2-CT930054 contract and work at POL was partly funded under contract to the U.K. Department of the Environment as part of its co-ordinated programme of research on the North Sea. A. J. Souza wishes to thank CONACyT, Mexico for the studentship provided. The authors thank Professor J. H. Simpson for his valuable comments during the development of the model and with the data interpretation.

\section{REFERENCES}

Csanady G. T. (1976) Mean circulation in shallow seas. Journal of Geophysical Research, 81, 5389-5399

Huthnance J. M., J. I. Allen, A. M. Davies, D. J. Hydes, I. D. James, J. E. Jones, G. E. Millward, D. Prandle, R. Proctor, D. A. Purdie, P. I. Statham, P. B. Tett, S. Thomson and R. G. Wood (1993) Towards water quality models. Philosophical Transactions of the Royal Society of London, A343, 569-584.

James I. D. (1986) A front-resolving sigma coordinate sea model with a simple hybrid advection scheme. Applied Mathematical Modelling, 10, 87-92.

James I. D. (1990) Numerical modelling of density-drive circulation in shelf seas. In: Modeling marine systems, vol. II, A. M. Davies, editor, CRC Press, Boca Raton, Florida, pp. 345-372.

James I. D. (1995) Advection schemes for shelf sea models. Journal of Marine Research (submitted).

Linden P. F. and J. E. Simpson (1988) Modulated mixing and frontogenesis in shallow seas and estuaries. Continental Shelf Research, 8, 1107-1127.

Mesinger F. and A. Arakawa (1976) Numerical methods used in atmospheric models, vol. 1. WMO, GARP Publication Series 17, 64 pp.

Munchow A. and R. W. Garvine (1993) Buoyancy and wind forcing of a coastal current. Journal of Marine Research, 51, 293-322.

Ou H. W. (1983) Some two-layer models of shelf-slope front: geostrophic adjustment and its maintenance. Journal of Physical Oceanography, 13, 1798-1808.

Sharples J. and J. H. Simpson (1994) Semi-diurnal and longer period stability cycles in the Liverpool Bay Region of Freshwater Influence. Continental Shelf Research, 15, 295-313.

Simpson J. H., W. G. Bos, F. Schirmer, A. J. Souza, T. P. Rippeth, S. E. Jones and D. Hydes (1993) Periodic stratification in the Rhine ROFI in the North Sea. Oceanologica Acta, 16(1), 23-32.

Simpson J. H. and A. J. Souza (1995) Semi-diurnal switching of stratification in the Rhine ROFI. Journal of Geophysical Research, 100, 7037-7044.

Souza A. J. and J. H. Simpson (1995) The modification of the tidal ellipses by stratification in the Rhine ROFI. Continental Shelf Research (in press).

Visser A. W., A. J. Souza, K. Hessner and J. H. Simpson (1994) The influence of water column stratification on tidal current profiles in a ROFI system. Oceanologica Acta, 17, 369-381. Yang H. O. and A. J. Przekwas (1992) A comparative study of advanced shock-capturing schemes applied to Burgers' equation. Journal of Computational Physics, 102, 139-159. 